\title{
Effects of prolonged nutrient restriction on baseline and periprandial plasma ghrelin concentrations of postpubertal Holstein heifers
}

\author{
M. E. Field, ${ }^{*}$ S. E. Deaver,† R. P. Rhoads, † R. J. Collier, ${ }^{*}$ and M. L. Rhoads $\dagger^{1}$ \\ ${ }^{*}$ Department of Animal Sciences, University of Arizona, Tucson 85721 \\ †Department of Animal and Poultry Sciences, Virginia Polytechnic Institute and State University, Blacksburg 24061
}

\begin{abstract}
Objectives of this study were to measure both daily and periprandial plasma ghrelin concentrations of postpubertal Holstein heifers during prolonged undernutrition. Following an acclimation period, Holstein heifers $[\mathrm{n}=10 ; 339.5 \pm 8.6 \mathrm{~kg}$ of body weight $(\mathrm{BW})]$ were fed ad libitum [well fed (WF); $\mathrm{n}=5$ ] or restricted to $50 \%$ of ad libitum intake [underfed (UF) $\mathrm{n}=5$ ) for 8 wk. Body condition scores (BCS) were recorded at the beginning and end of the treatment period, and weekly measurements of BW, plasma ghrelin, progesterone, and nonesterified fatty acids (NEFA) concentrations were obtained. Ovarian follicular and luteal structures were measured twice weekly via transrectal ultrasonography. Plasma ghrelin concentrations were also measured during a periprandial window bleed conducted at the end of the experiment. During the window bleed, samples were collected every 15 min between 0500 and $0900 \mathrm{~h}$, with feed offered at $0700 \mathrm{~h}$. Underfed heifers lost BW and BCS, whereas WF heifers gained weight and either increased or maintained BCS. Chronic underfeeding increased circulating ghrelin and NEFA concentrations. By wk 4 of the treatment period, circulating ghrelin concentrations of the UF heifers reached a plateau. Periprandial fluctuations in ghrelin concentrations were apparent as plasma ghrelin concentrations changed over time. Overall differences in periprandial plasma ghrelin concentrations were primarily due to prefeeding effects of plane of nutrition. Plasma ghrelin concentrations and change in BCS were negatively correlated such that heifers that lost the most BCS had the highest concentrations of circulating ghrelin. Two of the 5 UF heifers became anestrus by wk 3 of the treatment period. Despite being of similar age, the heifers that became anestrus had lower BW and plasma ghrelin concentrations than the UF heifers that continued to ovulate. In the current experiment, long-term undernutrition
\end{abstract}

Received March 22, 2013.

Accepted June 19, 2013.

${ }^{1}$ Corresponding author: rhoadsm@vt.edu elicited ghrelin responses similar to those reported for shorter durations of nutrient restriction in cattle and other ruminants. These results demonstrate that plane of nutrition is a chronic regulator of plasma ghrelin concentrations, and that these concentrations can be experimentally manipulated in postpubertal heifers for up to 8 wk with no evidence of an adaptive response.

Key words: dairy heifer, ghrelin

\section{INTRODUCTION}

In cattle and other species, the digestive tract is the primary source of circulating concentrations of ghrelin. The active form of bovine ghrelin is a 27-AA peptide with a hydrophobic posttranslational octanoylation at the serine 3 residue that is necessary for receptor activation (Dickin et al., 2004; van der Lely et al., 2004). Research during the last decade has shown that ghrelin exerts numerous physiological effects, but it is best known as a potent regulator of feed intake and a growth hormone secretagogue (Kojima et al., 1999; Hashizume et al., 2005; Wertz-Lutz et al., 2006).

Endocrine regulators of intake, such as ghrelin, have been studied extensively in rodents and humans, but have received comparably minuscule attention in regards to dairy production. On a chronic basis, ghrelin administration leads to persistent hyperphagia and weight gain in rodents (Wren et al., 2000). During periods of food deprivation (acute and chronic), circulating ghrelin levels increase in beef cattle, mice, rats, and humans (van der Lely et al., 2004; Wertz-Lutz et al., 2006, 2008). Ghrelin secretion also varies prandially, as plasma ghrelin concentrations increase immediately before feeding and decline after feeding in cattle, sheep, and pigs (Miura et al., 2004; Sugino et al., 2004; Bradford and Allen, 2008).

Evidence for a metabolic role of ghrelin in dairy cattle has been presented in multiple studies showing that plasma ghrelin concentrations are elevated in early lactation cows experiencing a state of negative energy balance (Itoh et al., 2005; Bradford and Allen, 2008) and in dairy cattle genetically selected for high milk production (Roche et al., 2006). Deciphering the specif- 
ic physiological effects of ghrelin in mature dairy cows is complicated by several confounding factors, including differing degrees of negative energy balance, cyclicity status, and clinical or subclinical disease. These factors are more easily controlled in nonlactating dairy heifers, whose plasma ghrelin concentrations can be manipulated experimentally. However, to date, plasma ghrelin concentrations of postpubertal dairy heifers during chronic nutrient restriction have not been described. As such, it is uncertain whether ghrelin concentrations remain steadily elevated for the duration of undernutrition or if the ruminant digestive system and metabolism eventually adapt in a manner that results in a secondary change (increase or decrease) in circulating ghrelin concentrations. It is also unknown whether prolonged severe undernutrition alters the pattern of the periprandial ghrelin response. Understanding the ghrelin response (both chronic and periprandial) to prolonged undernutrition is important because it (1) furthers our knowledge of long-term ghrelin regulation, and (2) provides a basis for future experiments during which lengthy sample collection periods are necessary (such as studying the effects of ghrelin on reproductive parameters). Therefore, the objective of this experiment was to characterize plasma ghrelin concentrations (chronic and periprandial) in dairy heifers subjected to prolonged nutrient restriction.

\section{MATERIALS AND METHODS}

\section{Animals}

This experiment was reviewed and approved by the Institutional Animal Care and Use Committee at the University of Arizona (Tucson). Postpubertal Holstein dairy heifers $(\mathrm{n}=10 ; 13.9 \pm 0.5 \mathrm{mo} ; 339.5 \pm 8.6 \mathrm{~kg}$ of BW; $3.2 \pm 0.1$ BCS) were sorted into individual pens and equally distributed between 2 treatment groups based upon BW, age, and BCS (where 1 = thin and 5 = fat; average of scores assessed by 2 individuals). Feed was offered at 0700 and $1700 \mathrm{~h}$, and refusals from the previous day were recorded at the $0700 \mathrm{~h}$ feeding. Because plasma ghrelin concentrations exhibit distinct diurnal and periprandial patterns, feeding and sampling times were strictly adhered to. All animals were fed for ad libitum intake for the first $7 \mathrm{~d}$ so that baseline feed intake values could be calculated for each individual. During the treatment period of the experiment ( $8 \mathrm{wk})$, the well-fed (WF; $\mathrm{n}=5)$ treatment group was fed ad libitum, whereas the underfed $(\mathbf{U F} ; \mathrm{n}=5)$ treatment group was restricted to $50 \%$ of ad libitum intake. To calculate the amount of feed that would be offered to the UF heifers, their actual individual intake was averaged over the $4 \mathrm{~d}$ before initiation of feed restriction.
Table 1. Composition of the ration fed to well-fed and underfed heifers

\begin{tabular}{lc}
\hline Component & \% of $\mathrm{DM}^{1}$ \\
\hline TDN & 55.1 \\
CP & 18.4 \\
NDF & 41.8 \\
ADF & 36.3 \\
Ash & 10.0 \\
Nitrogen & 2.9 \\
Fat & 1.6 \\
Calcium & 1.5 \\
Phosphorus & 0.3 \\
Magnesium & 0.3 \\
Sulfur & 0.4 \\
Potassium & 3.0 \\
Sodium & 0.2 \\
Chloride & 0.9 \\
Iron $(\mathrm{mg} / \mathrm{kg})$ & 319.4 \\
Manganese $(\mathrm{mg} / \mathrm{kg})$ & 75.4 \\
Copper $(\mathrm{mg} / \mathrm{kg})$ & 24.8 \\
Zinc $(\mathrm{mg} / \mathrm{kg})$ & 36.1 \\
Molybdenum $(\mathrm{mg} / \mathrm{kg})$ & 3.8 \\
NE $(\mathrm{Mcal} / \mathrm{kg}$ of DM) & 0.59 \\
\hline
\end{tabular}

${ }^{1}$ Dry matter content of the diet was $94.1 \%$.

On the first day of feed restriction, they were offered $75 \%$ of the 4 -d average. On the second day of restriction (and for the remainder of the experiment), they were offered $50 \%$ of the 4 -d average. Heifers were fed a dry alfalfa hay-based diet with a vitamin-mineral supplement. The diet was formulated to meet or exceed the nutritional demands for growth when fed ad libitum (NRC, 2001). The complete nutritional analysis of the diet is presented in Table 1. Body weight was recorded once weekly, $3 \mathrm{~h}$ after feeding. Body condition score was recorded at the beginning and end of the study.

\section{Experimental Protocol}

Weekly Blood Samples. Blood samples (approximately $8 \mathrm{~mL}$ ) for chronic analyses were collected by coccygeal venipuncture once weekly at $1000 \mathrm{~h}$. Blood was collected into an evacuated glass tube containing EDTA (BD Vacutainer; Franklin Lakes, NJ) and immediately placed on ice. After collection, plasma was immediately harvested via centrifugation at $1,500 \times$ $g$ for 15 min. Plasma samples were divided into 2 aliquots: (1) treated with $50 \mu \mathrm{L}$ of $1 N \mathrm{HCl}$ and $10 \mu \mathrm{L}$ of phenylmethylsulfonyl fluoride $\left(\mathrm{C}_{7} \mathrm{H}_{7} \mathrm{FO}_{2} \mathrm{~S}\right)$ per $\mathrm{mL}$ of plasma, according to kit instructions for analysis of ghrelin by RIA, or (2) untreated for measurement of progesterone and NEFA. All samples were frozen and stored at $-20^{\circ} \mathrm{C}$.

Transrectal Ovarian Ultrasonography. Ovarian follicular and luteal measurements were recorded twice weekly by means of transrectal ultrasonography (Aloka SSD-900V ultrasound scanner with a $7.5-\mathrm{MHz}$ probe, Aloka Co. Ltd., Tokyo, Japan). All ovarian structures 
$\geq 5 \mathrm{~mm}$ in size were individually measured (vertically and horizontally) and recorded onto ovarian maps. The number of antral follicles that were visible but $<5 \mathrm{~mm}$ in size were also recorded.

Periprandial Blood Samples. The experiment culminated with a periprandial window bleed. Unilateral indwelling jugular catheters were inserted 1 to $2 \mathrm{~d}$ before the window bleed (Rhoads et al., 2004). Blood samples (approximately $5 \mathrm{~mL}$ ) were collected from catheters every 15 min between 0500 and $0900 \mathrm{~h}$, with feeding occurring at $0700 \mathrm{~h}$. Samples were processed as described earlier and stored at $-20^{\circ} \mathrm{C}$ until analysis.

Plasma Analyses. Plasma ghrelin concentrations were measured by RIA specific for the biologically active form of ghrelin (cat no. GHRA-88HK, Millipore Inc., Billerica, MA). Although specific for the human acylated form of ghrelin, this kit has been previously validated for use with bovine plasma in our laboratory (Deaver et al., 2013). The intraassay CV averaged $8.64 \%$ (over 5 assays) and the interassay CV was $12.01 \%$.

Plasma NEFA concentrations were measured in weekly samples using a commercially available kit (NEFA C Kit, Wako Chemicals USA, Richmond, VA). The intraassay CV averaged $3.54 \%$ (over 5 assays) and the interassay CV was $3.43 \%$.

Plasma progesterone concentrations were determined by RIA kits (Coat-a-Count 17- $\alpha-\mathrm{OH}$ Progesterone, Siemens Medical Solutions Diagnostics, Los Angeles, CA) as described by Rhoads et al. (2008). Plasma progesterone intraassay $\mathrm{CV}$ was $1.85 \%$ (all samples were analyzed in a single assay).

\section{Calculations and Statistical Analyses}

Data were analyzed using the MIXED procedure of SAS (SAS Institute Inc., Cary, NC). The compound symmetry, unstructured, and autoregressive 1 covariance structures were tested and the most appropriate (lowest Akaike's information criterion, Akaike's information criterion with correction, and Bayesian information criterion values) was used for each analysis. Sample collection day (weekly samples) or time (window bleed samples) was included in the model as the repeated variable, and heifer was included as a random effect. The model used for the analyses of feed intake, BW, plasma NEFA, plasma progesterone, and weekly plasma ghrelin concentrations included effects of treatment, day, and treatment $x$ day interaction. Change in BCS was calculated for each individual heifer by subtracting their initial BCS from their ending BCS. Treatment differences in change in BCS were analyzed using the general linear model (GLM) procedure of SAS.
The model used to analyze plasma ghrelin concentrations during the window bleed included treatment, time, and treatment $\times$ time interaction. Periprandial ghrelin secretion patterns warranted further analysis of the data obtained during the window bleed. As such, the area under the curve (AUC) for each individual heifer was calculated by use of linear trapezoidal summation between successive pairs of ghrelin concentrations and time coordinates as described in Rhoads et al. (2009).

Results are reported as least squares means \pm standard error of the mean. Separation of means was conducted with the Tukey procedure of SAS. Correlations between variables were assessed with the CORR procedure of SAS. Statistical significance was declared at $P<0.05$ and tendencies were reported at $P<0.10$.

\section{RESULTS}

Before initiation of treatments, feed intake did not differ between treatment groups $(8.3 \pm 0.5 \mathrm{~kg} / \mathrm{d})$. As a result of the imposed treatments, feed intake between UF and WF heifers differed $(4.4 \pm 0.4$ and $9.0 \pm 0.4$ $\mathrm{kg} / \mathrm{d}$, respectively; $P<0.01)$. As anticipated, BW of the heifers was affected by treatment over time $(P<$ 0.01; Figure 1). The mean BW of the WF heifers slowly increased over the course of the study, whereas that of UF heifers decreased. Changes in BCS from the beginning to the end of the treatment period reflected the previously described differences in BW. Heifers began the treatment period at almost identical BCS. However, by the end of the experiment, WF heifers had maintained or improved their BCS $(0.15 \pm 0.10$ change in BCS), whereas UF heifers lost BCS $(-0.65 \pm 0.10$ change in BCS; $P<0.01$ ).

Weekly ghrelin concentrations were higher in the plasma of UF heifers than in that of WF heifers. Over time, plasma ghrelin concentrations of the 2 treatment groups diverged: concentrations in UF heifers increased, whereas concentrations decreased or remained unchanged in WF heifers (treatment $x$ day interaction, $P<0.05$; Figure 2). For UF heifers, weekly circulating ghrelin concentrations began to plateau at wk 4 of treatment. Weekly plasma ghrelin concentrations of the UF heifers increased numerically from wk 4 through wk 7 , but the increase was not statistically significant. There was a negative correlation between plasma ghrelin concentrations and change in BCS, such that heifers that lost the most BCS had the highest circulating concentrations of ghrelin, and heifers that gained BCS had lower circulating ghrelin concentrations $\left(\mathrm{R}^{2}=0.40\right.$; $P<0.05$; Figure 3 ).

Plasma NEFA concentrations were measured weekly as an indication of adipose tissue lipolysis, because 


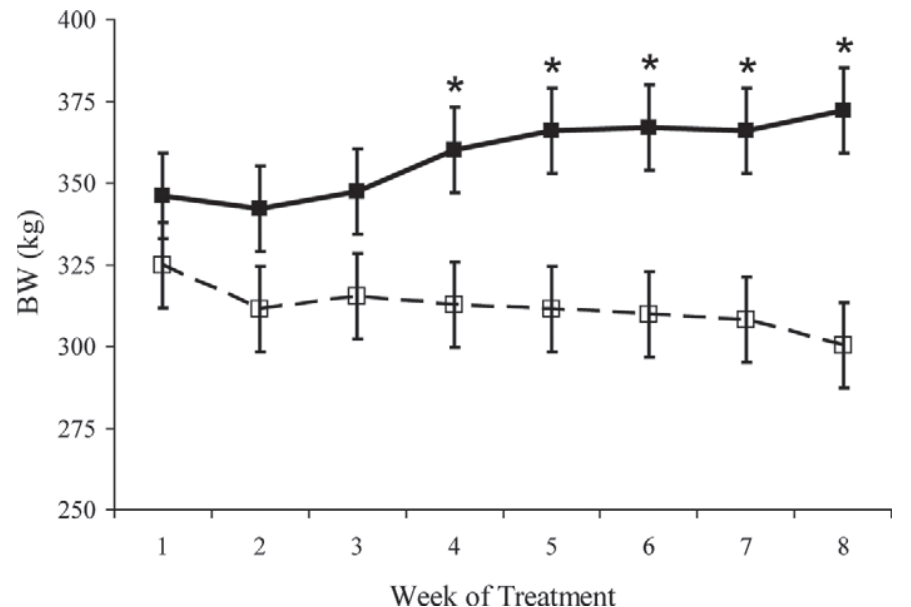

Figure 1. Body weight (kg) of underfed (UF; open symbols) and well-fed (WF; closed symbols) heifers for the 8-wk treatment period. Week $1 \mathrm{BW}$ was collected on the morning of the day that treatments began. Body weight was recorded $3 \mathrm{~h}$ after feeding. There was an interaction of treatment $\times$ time on $\mathrm{BW}(P<0.01)$. ${ }^{*}$ Data points differ at $P<0.05$ within a given week of treatment.

NEFA concentrations are thought to closely reflect calculated energy balance (Bauman et al., 1988). As anticipated, the plasma NEFA concentrations of the UF heifers were almost double the concentrations observed in WF heifers $(150.0 \pm 8.8$ and $88.2 \pm 7.7 \mu \mathrm{Eq} / \mathrm{L}$, respectively; $P<0.01)$. For both treatment groups, plasma NEFA concentrations decreased over time $(P$ $<0.01$; data not shown) and, as such, there was no interaction between treatment and time.

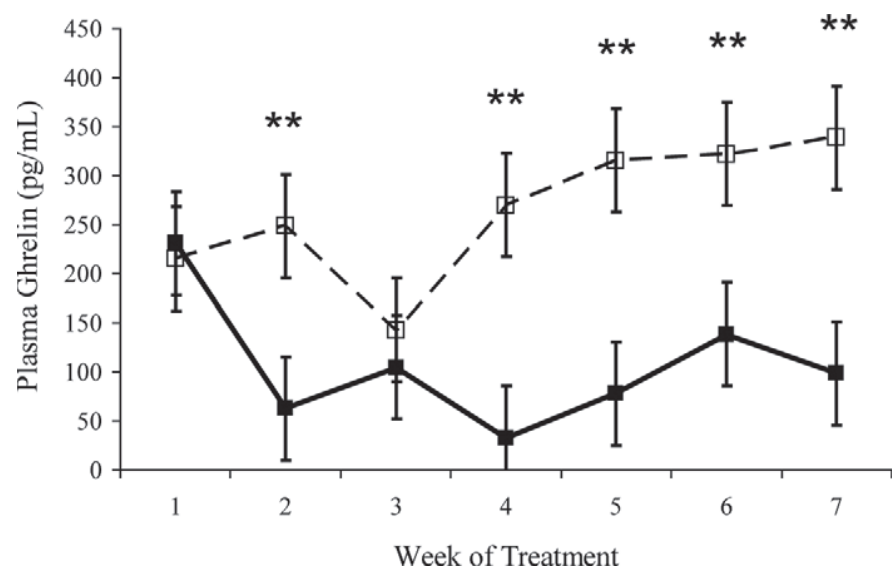

Figure 2. Weekly plasma ghrelin concentrations $(\mathrm{pg} / \mathrm{mL})$ of underfed (UF; open symbols) and well-fed (WF; closed symbols) heifers for the first 7 wk of the 8-wk treatment period (periprandial window bleed conducted in wk 8 instead of weekly sample). Week 1 plasma sample was collected on the morning of the day that treatments began. There was an interaction of treatment $\times$ time on weekly plasma ghrelin concentrations $(P<0.05)$. ${ }^{* *}$ Data points differ at $P \leq 0.01$ within a given week of treatment.

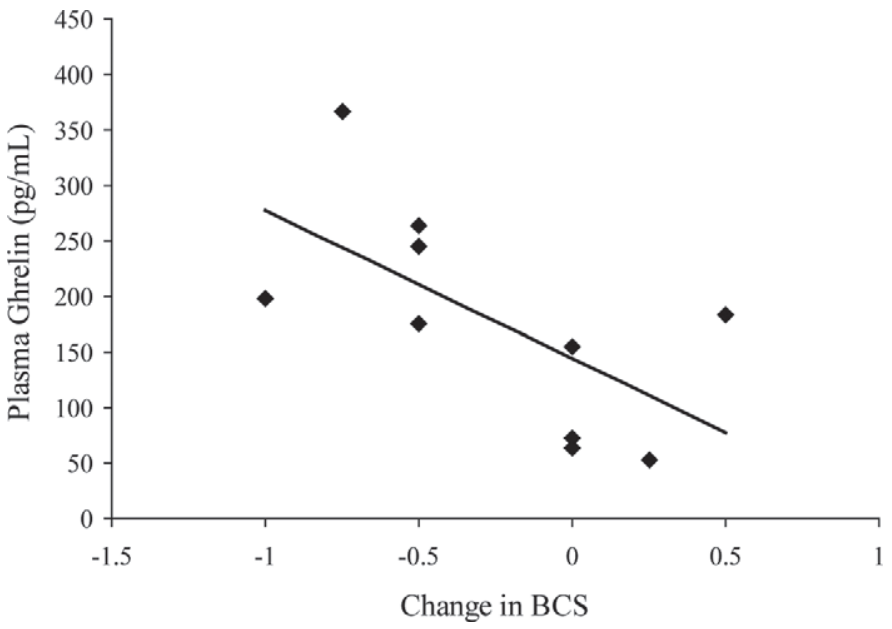

Figure 3. Regression of mean weekly plasma ghrelin concentrations on change in BCS during the treatment period $\left(\mathrm{R}^{2}=0.40 ; P<\right.$ $0.05)$. Change in BCS was calculated for each heifer by subtracting pretreatment BCS from the BCS recorded after the 8-wk treatment period. All well-fed (WF) heifers maintained or gained BCS (0 or greater change in BCS) whereas all underfed (UF) heifers lost BCS (change in $\mathrm{BCS}<0$ ) during the treatment period.

Plasma ghrelin concentrations during the periprandial window bleed were affected by treatment $(P<$ $0.01)$ and time $(P<0.01)$, with a tendency for an interaction between treatment and time $(P=0.08$; Figure 4). Plasma ghrelin concentrations undergo dynamic changes during the periprandial period. To more accurately account for these dynamic changes, the AUC was calculated for each heifer and analyzed accordingly. When considering plasma ghrelin concentrations for the entire window bleed, AUC was greater in UF heifers than in WF heifers $(P<0.01$; Table 2$)$. When pre- and postfeeding concentrations were analyzed separately, the AUC of prefeeding ghrelin concentrations differed $(P<0.01)$, whereas the postfeeding AUC only tended to differ between treatments $(P=0.08)$. This suggests that the overall difference in $\mathrm{AUC}$ is primarily due to prefeeding plasma ghrelin concentrations rather than postfeeding concentrations. Further analysis confirmed these observations, in that the difference between the prefeeding and postfeeding AUC tended to differ between the treatment groups $(P=0.10$; Table 2$)$.

By the third week of the treatment period, $2 \mathrm{UF}$ heifers were no longer ovulating and had become anestrus. The other 3 UF heifers continued to ovulate regularly for the entire treatment period. These results were observed by transrectal ultrasonography of the ovaries and verified by comparison with plasma progesterone concentrations (data not shown). Despite being of similar age, the UF heifers that continued to cycle had higher mean BW than those that ceased cycling $(329.4 \pm 3.5$ vs. $294.4 \pm 4.2 \mathrm{~kg}$, respectively; $P<0.01)$. 
Table 2. Area under the curve $(\mathrm{AUC} ; \mathrm{pg} / \mathrm{mL} \times \mathrm{min})$ values for plasma ghrelin concentrations during the 4-h periprandial window bleed

\begin{tabular}{|c|c|c|c|c|}
\hline \multirow[b]{2}{*}{ Item } & \multicolumn{2}{|c|}{ Treatment $^{1}$} & \multirow[b]{2}{*}{ SEM } & \multirow[b]{2}{*}{$P$-value } \\
\hline & WF & UF & & \\
\hline All samples & 10,579 & 28,225 & 3,481 & $<0.01$ \\
\hline Prefeeding ${ }^{2}$ & 6,203 & 17,842 & 1,969 & $<0.01$ \\
\hline Postfeeding ${ }^{2}$ & 4,376 & 10,383 & 2,124 & 0.08 \\
\hline Difference & 1,828 & 7,459 & 2,158 & 0.10 \\
\hline
\end{tabular}

${ }^{1}$ Heifers were either well fed (WF) or underfed (UF) for $56 \mathrm{~d}$ before the window bleed.

${ }^{2}$ Blood samples were collected at 15-min intervals for $2 \mathrm{~h}$ prefeeding and $2 \mathrm{~h}$ postfeeding.

Interestingly, plasma ghrelin concentrations of underfed heifers that continued to cycle tended to be higher than those of their acyclic counterparts $(258.5 \pm 24.0$ vs. $178.9 \pm 23.4 \mathrm{pg} / \mathrm{mL}$, respectively; $P<0.10)$. The AUC values for periprandial ghrelin followed a similar trend for cyclic versus acyclic UF heifers (data not shown).

\section{DISCUSSION}

Undoubtedly, the heifers in the UF group were undernourished for the duration of this experiment and existed in a state of NEB, as demonstrated by decreased $\mathrm{BW}$, decreased BCS, increased NEFA concentrations, and loss of cyclicity ( 2 of 5 heifers). In previous studies of early-lactating dairy cows and nutrient-restricted steers, ghrelin concentrations were elevated during periods of NEB (Bradford and Allen, 2008; Wertz-Lutz et al., 2008). Furthermore, the characteristic increase in ghrelin concentrations during NEB is observed across

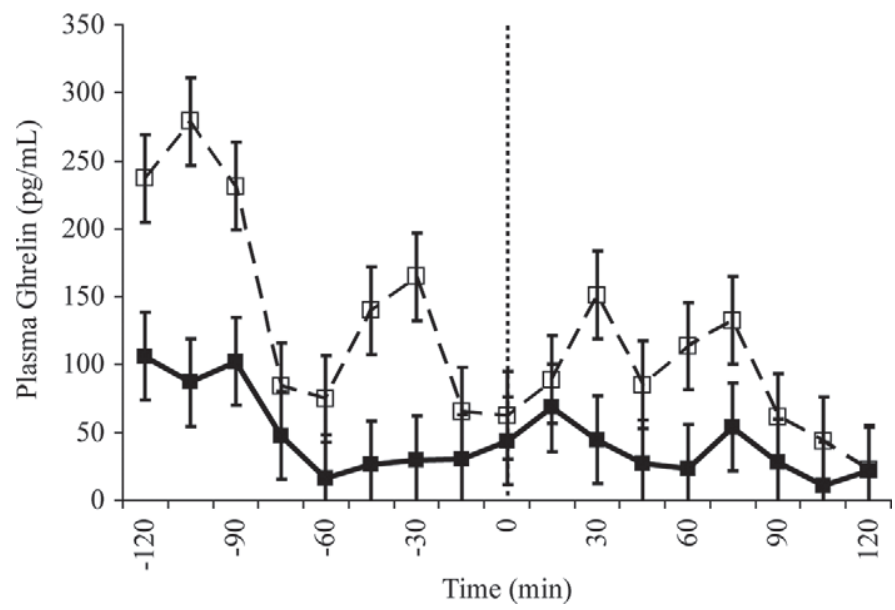

Figure 4. Plasma ghrelin concentrations for well-fed (WF; closed symbols) and underfed (UF; open symbols) heifers during the periprandial window bleed. Blood samples were collected for $2 \mathrm{~h}$ prefeeding and $2 \mathrm{~h}$ postfeeding. Animals were fed immediately after their time zero blood sample was collected (indicated by dashed vertical line). Overall, plasma ghrelin concentrations were significantly affected by treatment $(P<0.01)$ and time $(P<0.01)$, with a tendency for an interaction between treatment and time $(P=0.08)$. several species, as similar results have been described following experiments involving feed-restricted mice, rats, sheep, and humans (Hayashida et al., 2001; van der Lely et al., 2004; Relling et al., 2010). The results of the current study agree with those reported throughout the literature: plasma ghrelin concentrations were elevated in response to nutrient restriction (UF) of postpubertal Holstein heifers. Furthermore, ghrelin concentrations were negatively correlated with change in BCS, indicating that as BCS decreased, plasma ghrelin concentrations increased. It is important to note that this experiment is unique because of the duration of nutrient restriction. In the current experiment, heifers were nutrient restricted for $56 \mathrm{~d}$ compared with the 21-d restriction that was imposed on steers by Wertz-Lutz et al. (2008). Weekly plasma ghrelin concentrations of the UF heifers stabilized and began to plateau at wk 4 of treatment. After wk 4, we observed no further changes in chronic ghrelin concentrations of the UF heifers. This indicates that, at least for the first $7 \mathrm{wk}$ of undernutrition, there were no adaptive responses that cause a net change in circulating ghrelin concentrations.

Previous studies in cattle and other species have demonstrated characteristic changes in circulating ghrelin concentrations relative to feed intake. In general, plasma ghrelin concentrations are high before feeding and then quickly decrease following feeding (Wertz-Lutz et al., 2006; Bradford and Allen, 2008). The window bleed portion of the current experiment was designed to measure periprandial changes in ghrelin concentrations for heifers that had been chronically WF or UF. The tendency for a treatment effect mirrors the results from the weekly samples in that UF heifers had higher circulating concentrations of ghrelin. The significant effect of time implies that characteristic changes in ghrelin concentrations occurred in relation to feeding. In general, ghrelin concentrations were, indeed, elevated before feeding and declined following feeding. However, closer analysis of the means revealed that the heifers in the current experiment experienced several peaks and troughs in terms of ghrelin secretion. The reasons 
for these oscillating concentrations of plasma ghrelin are not completely understood. Although they may be related to the prolonged duration of the treatment period, we believe it is most likely a behavioral response. Because the window bleed began at $0500 \mathrm{~h}(2 \mathrm{~h}$ before the heifers would normally be fed), we suspect that the heifers anticipated feeding and that this anticipation affected ghrelin secretion. And due to the nature of the feeding regimen, all WF heifers had feed in their bunks during the prefeeding portion of the window bleed. In contrast, none of the UF heifers had feed remaining in their bunks. In rodents and pigs with an established feeding time, ghrelin increased before feeding; however, this event was not observed in freely fed animals, suggesting that anticipation of the meal may affect circulating ghrelin concentrations prefeeding (Sugino et al., 2002; Drazen et al., 2006; Reynolds et al., 2010).

Although it was not the intent of this experiment, 2 of the 5 heifers assigned to the UF treatment ceased estrous cyclicity approximately midway through the treatment period. Interestingly, plasma ghrelin concentrations of these heifers tended to be lower than those of their cyclic counterparts (the other 3 UF heifers). At first glance, it would appear that these observations are contrary to most published evidence in other species. In almost all cases, LH secretion is inhibited in mammals exposed to elevated ghrelin concentrations (endogenous or exogenous; Furuta et al., 2001; Ogata et al., 2009; Ahmed et al., 2012; Kluge et al., 2012; Scheid et al., 2013). This suppression of LH would presumably set into motion a cascade of events ultimately resulting in a cessation of ovulation and cyclicity. Closer examination of the literature, however, indicates that an intricate synergy exists between ghrelin and the sex steroids. Fernández-Fernández et al. (2007) investigated the interrelationships between ghrelin, ovarian inputs, nitric oxide, and hypothalamic differentiation. During these experiments, ghrelin stimulated in vitro LH secretion from the anterior pituitaries of prepubertal female rats. Estrogen is also known to selectively alter the production and biological activity of ghrelin rather than vice versa, which provides further evidence for this complex interrelationship (Kok et al., 2008; Paulo et al., 2008). As such, states of anestrus may inherently prevent estrogen-stimulated production of ghrelin, which is consistent with the lower ghrelin concentrations observed in the anestrus heifers from the current experiment.

Because BW is positively associated with attainment of puberty (Chelikani et al., 2003; Archbold et al., 2012), we suspect that the UF heifers that ceased estrous cyclicity had completed fewer postpubertal estrous cycles than their contemporaries (i.e., they attained puberty after their contemporaries). Those heifers that stopped cycling were $11 \%$ lighter than the UF heifers that continued to cycle despite being similar in age. As such, the differences in ghrelin concentrations, ovarian inputs and hypothalamic maturity may have collectively caused these heifers to succumb to nutritionally induced anestrus.

Circulating plasma ghrelin concentrations of the postpubertal Holstein heifers from the current study were comparable to those of mature Holstein cows. Concentrations in WF heifers more closely resembled those of nonlactating cows, whereas concentrations in UF heifers resembled those of lactating cows (Miura et al., 2004; Cossel et al., 2009). Despite the severity of the UF treatment, however, plasma NEFA concentrations did not approach the magnitude of those observed in early lactation dairy cattle (Bradford and Allen, 2008; Rhoads et al., 2009). This is not surprising given the inherent differences between the metabolism of an underfed animal and the metabolism of a lactating animal. These results do suggest, however, that under appropriately controlled experimental conditions, postpubertal heifers could be used as model animals in future experiments aimed at elucidating exclusive effects of ghrelin.

\section{ACKNOWLEDGMENTS}

This research project was supported by National Research Initiative Competitive Grant No. 2005-3520316041 from the USDA Cooperative State Research, Education, and Extension Service (Washington, DC).

\section{REFERENCES}

Ahmed, H. H., W. K. Khalil, W. G. Shousha, E. S. El-Sayed, E. F. Eskander, and R. E. Selim. 2012. Effect of food restriction on reproductive-related genes and reproductive hormones in adult female rats. Eur. Rev. Med. Pharmacol. Sci. 16:1680-1690.

Archbold, H., L. Shalloo, E. Kennedy, K. M. Pierce, and F. Buckley. 2012. Influence of age, body weight and body condition score before mating start date on the pubertal rate of maiden HolsteinFriesian heifers and implications for subsequent cow performance and profitability. Animal 6:1143-1151.

Bauman, D. E., C. J. Peel, W. D. Steinhour, P. J. Reynolds, H. F. Tyrrell, A. C. Brown, and G. L. Haaland. 1988. Effect of bovine somatotropin on metabolism of lactating dairy cows: Influence on rates of irreversible loss and oxidation of glucose and nonesterified fatty acids. J. Nutr. 118:1031-1040.

Bradford, B. J., and M. S. Allen. 2008. Negative energy balance increases periprandial ghrelin and growth hormone concentrations in lactating dairy cows. Domest. Anim. Endocrinol. 34:196-203.

Chelikani, P. K., D. R. Glimm, and J. J. Kennelly. 2003. Short communication: Tissue distribution of leptin and leptin receptor mRNA in the bovine. J. Dairy Sci. 86:2369-2372.

Cossel, S. E., M. E. Field, M. V. Skrzypek, S. R. Sanders, S. L. Marion, J. B. Wheelock, S. R. Hartman, Y. Yuxi, P. B. Hoyer, R. J. Collier, R. P. Rhoads, L. H. Baumgard, and M. L. Rhoads. 2009. Effects of heat stress on ghrelin secretion in lactating dairy cattle. J. Dairy Sci. 92(Suppl. 1):72. (Abstr.)

Deaver, S. E., P. B. Hoyer, S. M. Dial, M. E. Field, R. J. Collier, and M. L. Rhoads. 2013. Localization of ghrelin and its receptor in the reproductive tract of Holstein heifers. J. Dairy Sci. 96:150-157. 
Dickin, J. C., T. D. Thue, and F. C. Buchanan. 2004. An alternative splice site in ghrelin is missing in ruminants. Anim. Genet. 35:411-412.

Drazen, D. L., T. P. Vahl, D. A. D'Alessio, R. J. Seeley, and S. C. Woods. 2006. Effects of a fixed meal pattern on ghrelin secretion: Evidence for a learned response independent of nutrient status. Endocrinology 147:23-30.

Fernández-Fernández, R., M. Tena-Sempere, J. Roa, J. M. Castellano, V. M. Navarro, E. Aguilar, and L. Pinilla. 2007. Direct stimulatory effect of ghrelin on pituitary release of LH through a nitric oxidedependent mechanism that is modulated by estrogen. Reproduction 133:1223-1232.

Furuta, M., T. Funabashi, and F. Kimura. 2001. Intracerebroventricular administration of ghrelin rapidly suppresses pulsatile luteinizing hormone secretion in ovariectomized rats. Biochem. Biophys. Res. Commun. 288:780-785.

Hashizume, T., M. Horiuchi, S. Nonaka, E. Kasuya, M. Kojima, H. Hosoda, and K. Kangawa. 2005. Effects of ghrelin on growth hormone secretion in vivo in ruminants. Regul. Pept. 126:61-65.

Hayashida, T., K. Murakami, K. Mogi, M. Nishihara, M. Nakazato, M. S. Mondal, Y. Horii, M. Kojima, K. Kangawa, and N. Murakami. 2001. Ghrelin in domestic animals: Distribution in stomach and its possible role. Domest. Anim. Endocrinol. 21:17-24.

Itoh, F., T. Komatsu, M. Yonai, T. Sugino, M. Kojima, K. Kangawa, Y. Hasegawa, Y. Terashima, and K. Hodate. 2005. GH secretory responses to ghrelin and GHRH in growing and lactating dairy cattle. Domest. Anim. Endocrinol. 28:34-45.

Kluge, M., P. Schussler, D. Schmidt, M. Uhr, and A. Steiger. 2012. Ghrelin suppresses secretion of luteinizing hormone (LH) and follicle-stimulating hormone (FSH) in women. J. Clin. Endocrinol. Metab. 97:E448-E451.

Kojima, M., H. Hosoda, Y. Date, M. Nakazato, H. Matsuo, and K. Kangawa. 1999. Ghrelin is a growth-hormone-releasing acylated peptide from stomach. Nature 402:656-660.

Kok, P., R. C. Paulo, M. Cosma, K. L. Mielke, J. M. Miles, C. Y. Bowers, and J. D. Veldhuis. 2008. Estrogen supplementation selectively enhances hypothalamo-pituitary sensitivity to ghrelin in postmenopausal women. J. Clin. Endocrinol. Metab. 93:4020-4026.

Miura, H., N. Tsuchiya, I. Sasaki, M. Kikuchi, M. Kojima, K. Kangawa, Y. Hasegawa, and Y. Ohnami. 2004. Changes in plasma ghrelin and growth hormone concentrations in mature Holstein cows and three-month-old calves. J. Anim. Sci. 82:1329-1333.

NRC. 2001. Nutrient Requirements of Dairy Cattle. 7th rev. ed. Natl. Acad. Press, Washington, DC.

Ogata, R., T. Matsuzaki, T. Iwasa, M. Kiyokawa, N. Tanaka, A. Kuwahara, T. Yasui, and M. Irahara. 2009. Hypothalamic ghrelin suppresses pulsatile secretion of luteinizing hormone via beta-endorphin in ovariectomized rats. Neuroendocrinology 90:364-370.

Paulo, R. C., R. Brundage, M. Cosma, K. L. Mielke, C. Y. Bowers, and J. D. Veldhuis. 2008. Estrogen elevates the peak overnight production rate of acylated ghrelin. J. Clin. Endocrinol. Metab. 93:4440-4447.
Relling, A. E., J. L. Pate, C. K. Reynolds, and S. C. Loerch. 2010. Effect of feed restriction and supplemental dietary fat on gut peptide and hypothalamic neuropeptide messenger ribonucleic acid concentrations in growing wethers. J. Anim. Sci. 88:737-748.

Reynolds, C. B., A. N. Elias, and C. S. Whisnant. 2010. Effects of feeding pattern on ghrelin and insulin secretion in pigs. Domest. Anim. Endocrinol. 39:90-96.

Rhoads, M. L., R. O. Gilbert, M. C. Lucy, and W. R. Butler. 2004. Effects of urea infusion on the uterine luminal environment of dairy cows. J. Dairy Sci. 87:2896-2901.

Rhoads, M. L., J. P. Meyer, W. R. Lamberson, D. H. Keisler, and M. C. Lucy. 2008. Uterine and hepatic gene expression in relation to days postpartum, estrus, and pregnancy in postpartum dairy cows. J. Dairy Sci. 91:140-150.

Rhoads, M. L., R. P. Rhoads, M. J. VanBaale, R. J. Collier, S. R. Sanders, W. J. Weber, B. A. Crooker, and L. H. Baumgard. 2009. Effects of heat stress and plane of nutrition on lactating Holstein cows: I. Production, metabolism, and aspects of circulating somatotropin. J. Dairy Sci. 92:1986-1997.

Roche, J. R., A. J. Sheahan, L. M. Chagas, and D. P. Berry. 2006 Short communication: Genetic selection for milk production increases plasma ghrelin in dairy cows. J. Dairy Sci. 89:3471-3475.

Scheid, J. L., M. J. De Souza, B. R. Hill, H. J. Leidy, and N. I. Williams. 2013. Decreased luteinizing hormone pulse frequency is associated with elevated 24-hour ghrelin after calorie restriction and exercise in premenopausal women. Am. J. Physiol. Endocrinol. Metab. 304:E109-E116.

Sugino, T., Y. Hasegawa, Y. Kurose, M. Kojima, K. Kangawa, and Y. Terashima. 2004. Effects of ghrelin on food intake and neuroendocrine function in sheep. Anim. Reprod. Sci. 82-83:183-194.

Sugino, T., J. Yamaura, M. Yamagishi, A. Ogura, R. Hayashi, Y. Kurose, M. Kojima, K. Kangawa, Y. Hasegawa, and Y. Terashima. 2002. A transient surge of ghrelin secretion before feeding is modified by different feeding regimens in sheep. Biochem. Biophys. Res. Commun. 298:785-788.

van der Lely, A. J., M. Tschop, M. L. Heiman, and E. Ghigo. 2004. Biological, physiological, pathophysiological, and pharmacological aspects of ghrelin. Endocr. Rev. 25:426-457.

Wertz-Lutz, A. E., J. A. Daniel, J. A. Clapper, A. Trenkle, and D. C. Beitz. 2008. Prolonged, moderate nutrient restriction in beef cattle results in persistently elevated circulating ghrelin concentrations. J. Anim. Sci. 86:564-575.

Wertz-Lutz, A. E., T. J. Knight, R. H. Pritchard, J. A. Daniel, J. A. Clapper, A. J. Smart, A. Trenkle, and D. C. Beitz. 2006. Circulating ghrelin concentrations fluctuate relative to nutritional status and influence feeding behavior in cattle. J. Anim. Sci. 84:32853300 .

Wren, A. M., C. J. Small, H. L. Ward, K. G. Murphy, C. L. Dakin, S. Taheri, A. R. Kennedy, G. H. Roberts, D. G. Morgan, M. A. Ghatei, and S. R. Bloom. 2000. The novel hypothalamic peptide ghrelin stimulates food intake and growth hormone secretion. Endocrinology 141:4325-4328. 